\title{
Agenda problemática de El primer nueva corónica y buen gobierno de Guaman Poma de Ayala
}

\author{
Carlos García Miranda \\ Universidad de Salamanca \\ benke_04@yahoo.es
}

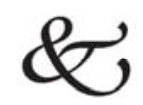

\section{Resumen}

El presente estudio realiza una revisión de la recepción crítica sobre $E l$ primer nueva corónica y buen gobierno, atribuido a Felipe Guaman Poma de Ayala. El corpus crítico abarca desde las primeras décadas del siglo XX hasta el 2010. El objetivo es presentar una descripción actualizada de las distintas perspectivas críticas desde las que se ha abordado esta crónica.

Palabras claves: Literatura colonial, crónicas andinas, Guaman Poma de Ayala.

\begin{abstract}
This study provides a review of the critical reception of El primer nueva corónica y buen gobierno, atributted to Felipe Guaman Poma de Ayala. The critical corpus approach the studies since the first decades of the 20th century until to our days. The objective is a description of the distinct critical perspectives of this chronicle.

Key words: Colonial literatura, andean chronicles, Guaman Poma de Ayala.
\end{abstract}

\section{Introducción}

Los estudios más elaborados sobre El primer nueva corónica y buen gobierno (2006 [1613]) surgen en las últimas dos décadas del siglo $\mathrm{XX}^{1}$, periodo en

1 Si bien es cierto que la agenda crítica con respecto a El primer nueva corónica y buen gobierno se desarrolló a lo largo del siglo XX, es a finales de ese siglo, luego de que en la década del ochenta aparecieran ediciones más legibles del manuscrito, donde empieza a surgir las principales líneas de lectura.

LETRAS 81 (116), 2010 


\section{Carlos García Miranda}

que los estudios humanísticos estuvieron dominados por las problemáticas de la posmodernidad, especialmente de aquellas que discutían la pertinencia de las fronteras disciplinarias ${ }^{2}$. En efecto, hacia finales de los años ochenta, esta situación llevó a considerar las investigaciones filosóficas, científicas e históricas como literarias ${ }^{3}$, redefiniendo así los fundamentos de los estudios humanísticos. En el ámbito de la antropología, por ejemplo, surgió la antropología posmoderna, perspectiva teórica que concibió la práctica antropológica como una escritura etnográfica ${ }^{4}$. En este marco, aparecieron líneas de investigación como la meta-etnografía o meta-antropología, cuyo fundamento fue la consideración de la etnografía como si fuera una expresión literaria, interesándose en estudiar los aspectos retóricos de la escritura etnográfica. Otra línea fue la etnografía experimental, que se caracterizó por problematizar la práctica etnográfica, es decir, las metodologías del trabajo de campo con las que se elaboraba las monografías etnográficas. Una tercera

2 Entre los autores que impulsaron estas corrientes de pensamiento podemos señalar como centrales a Jaques Derrida, Jean Braudillard, Francois Lyotard, Gianni Vattimo, Michael Foucault y Mijail Bajtín.

3 Al respecto, afirma Geertz: "Esta confusión de géneros es más que el hecho de que Harry Houdini o Richard Nixon se vuelvan de pronto personajes de novela, o que las juergas mortíferas del medio oeste se describan como si las hubiera imaginado un novelista gótico. Se trata de que las investigaciones filosóficas parecen críticas literarias (piénsese en Stanley Cavell escribiendo sobre Becket o Thoreau, en Sartre escribiendo sobre Flaubert), las discusiones científicas se asemejan a fragmentos de bellas letras (Lewis Thomas, Loren Eiseley), fantasías barrocas se presentan como observaciones empíricas inexpresivas (Borges, Barthelme), aparecen historias que consisten en ecuaciones y tablas o en testimonios jurídicos (Fogel y Engerman, Le Roi Ladurie), documentos que parecen confesiones verdaderas (Mailer), parábolas que pasan por ser etnografías (Castaneda), tratados teóricos expuestos como recuerdos de viaje (Lévi-Strauss), argumentos ideológicos presentados como investigaciones historiográficas (Edward Said), estudios epistemológicos construidos como tratados políticos (Paul Feyerabend), polémicas metodológicas arregladas como si fueran memorias personales (James Watson), El fuego pálido de Nabokov, ese objeto imposible hecho de poesía y ficción, notas al pie de página e imágenes de la clínica, se asemeja a los tiempos que corren; lo único que falta es teoría cuántica en verso o biografía expresada en álgebra” (Geerzt, 1994, pp. 31-32).

4 De acuerdo con Lorite Mena, habría que entenderla “(...) en primer lugar, [como] una denuncia que proviene de la Antropología misma en una de sus vertientes actuales más autocríticas: el amplio movimiento calificado como «antropología postmoderna»'. Los autores que la representan repliegan su posición de observadores para situarse en una perspectiva «meta-etnológica» (o meta-antropológica: filosófica) desde la que introducen una incertidumbre epistemológica. El etnógrafo aparece inmerso en una observación participante - lo cual sería la condición básica del realismo etnográfico y de la fiabilidad de su testimonio-; pero también produce como autor, como un intérprete que al «hablar por [otros]» ordena el discurso de los otros para «dar un sentido» que es su sentido. Un desdoblamiento epistemológico que permite a C. Geertz, de manera tajante, considerar ficciones los textos antropológicos: «Ficciones en el sentido de que son algo "hecho", algo "formado ", "compuesto" -que es significativo de ficción- no necesariamente falsas o inefectivas o meros experimentos mentales de 'como sí'” (Lorite Mena, 1995, pp. 9-10). 
y última línea fue el vanguardismo posmoderno, mucho más radical que las anteriores, pues propuso una epistemología irracionalista que cuestionaba el proyecto científico etnográfico y la autoridad etnográfica, develando el uso del montaje y el collage en sus investigaciones (Reynoso, 1998: 22).

En general, estas líneas se inspiraron en las ideas de Geertz (1998), quien planteó que las interpretaciones antropológicas "son ficciones en el sentido de que son algo "hecho", algo "formado", "compuesto"-que es la significación de ficción- no necesariamente falsas o inefectivas o meros experimentos mentales de "como si" (pp. 63-64).

En el campo de la historia se produjeron cambios similares como consecuencia del impacto de corrientes de pensamiento como la fenomenología, la hermenéutica y el estructuralismo. Quizás, como argumentó G. Vattimo (1985), sea Nietzsche el que con más fuerza violentó los fundamentos epistemológicos de la historia al plantear el problema de "la enfermedad de la historia", tesis que impulsó los debates en torno a los estatutos cientificistas de la historia. La enfermedad de la historia consiste, según Nietzsche, en que ésta debe, ante todo, escribirse. En ese sentido, el acto previo de la investigación histórica no son los hechos, sino la escritura, de tal modo que el problema inicial de toda narración histórica se reduce a un problema de estilo. Desde ese momento, la "verdad" histórica pasaría a ser una verdad "discursiva", pues, como plantea Jorge Lozano (1987), "un discurso como el histórico que quiere probar lo que dice es verdad, presentará el efecto de verdad, modalizando los enunciados; atender a ellos y observar sus transformaciones puede permitirnos descubrir las estrategias de un enunciador que se empeña en ocultarse" (p. 209).

A partir de estos procesos, la investigación literaria, sobre todo la teoría literaria, comenzó a ocupar un lugar expectante en la cartografía humanística. El punto de conexión teórica entre las preocupaciones literarias y las de otras disciplinas se establece en tópicos como la mimesis, los recursos retóricos y la naturaleza de la ficción literaria, temas que implican discutir los fundamentos de las otras disciplinas, como la historia y la antropología. Precisamente, El primer nueva corónica y buen gobierno entra en diálogo con estas problemáticas al presentarse como un texto que discute el principio de verdad documentada de la historia y revela la sujeción de la información antropológica a los principios de argumentación retórica, necesaria para fundamentar su proyecto políticoeconómico.

5 De acuerdo con Vattimo: "Nietzsche habla de enfermedad histórica ante todo para subrayar que el exceso de conciencia historiográfica que él ve como característico del siglo XIX es también, y de forma inseparable, incapacidad de crear una nueva historia. La enfermedad es histórica tanto porque es historiográfica, como porque tiene que ver con la historia como res gestae, y esto es negativo, puesto que es la incapacidad de producir una historia propia derivada del excesivo interés por la ciencia de las cosas pasadas" ( p. 24). 


\section{Agendas problemáticas}

El proceso seguido por El primer nueva corónica y buen gobierno desde su redacción en el Perú colonial, entre finales del s. XVI y comienzos del s. XVII, hasta su descubrimiento en 1908 en Dinamarca y posterior edición y estudio, contempla no sólo un amplio recorrido geográfico, sino también un conjunto de circunstancias y posibilidades aún no discernidas del todo, pero que ha llevado a diversos estudiosos a plantear una serie de temas y líneas de investigación.

Uno de los primeros temas fue la fijación de la fecha de redacción del manuscrito. Tempranamente, Richard Pietschmann planteó, dejando de lado la afirmación de Guaman Poma de que le llevó más de veinte años escribirla, que fue escrita en 1613, pues los acontecimientos narrados en el manuscrito "no se remontan más allá de 1600” (1908: 83), propuesta compartida por Means, quien afirmó que "en realidad, parece ésta [1613] la fecha en que fue concluida" (1923: 105). Últimamente, han compartido, en general, esta tesis Rolena Adorno (2002), afirmando que "el gran número de referencias [...] a los años 1612 y 1613, que se encuentran desde los primeros capítulos del manuscrito en adelante, sugieren que el texto íntegro de su borrador final [...] fue preparado desde algún momento en 1612 hasta principios de 1615” (s.n.), y también Juan M. Ossio, quien afirma que "nos da la impresión que el conjunto de la crónica se armó de manera unitaria, con su tabla de contenidos, entre 1612 y 1613" (2008: 46).

Otros estudiosos, tratando de ser fieles al dato proporcionado por el mismo manuscrito sobre que tardó veinte o treinta años, han propuesto un arco temporal mayor, como R. Clements Markham quien sugirió como fechas posibles 1583 a 1613 (1939: 104), y Julio C. Tello, que propone las fechas de 1567 y 1613 (1939: 5). Asumiendo una posición de consenso en esta discusión, Porras Barrenechea, partiendo de las afirmaciones de Pietschmann, argumentará con mayor rigor que, aunque "desde las primeras páginas de la crónica se comprueba que ésta fue escrita, en su forma presente, no sólo después de 1587 sino después de 1600 y quizás entre 1613 y 1615” (1986: 616), es posible que la primera parte -Nueva corónica- se escribiese "antes de 1600, para lo que recogería datos durante 20 años, y que se decidiera a escribir la segunda parte -el Buen Gobierno- precisamente el año 1613" (1986: 617). Una posición similar asume Padilla Bendezú al plantear que "Huamán Poma reunió sus notas en treinta años; pero la labor material de escribir la obra demandó menor tiempo" (1979: 82), concluyendo más adelante que debió reunir sus datos desde 1583, fecha en que supone que Guaman Poma fue expulsado de su provincia, y concluir el manuscrito en 1613, fecha referida en el manuscrito como año de su término. 
Un segundo tema fue la existencia de un borrador del manuscrito. Nuevamente Pietschmann tempranamente reparó en esa posibilidad, señalando que "algunas partes [del manuscrito] pueden haber sido tomadas de una versión previa, suprimida o alterada por el autor” (1975: 201). Años después retomó esta tesis Porras Barrenechea, pero señalando que lo copiado fue sólo la parte de Nueva corónica -que debió comenzar a redactarse antes de 1600-, cuando la integró a la parte de Buen gobierno, escrita entre 1613 y 1615, como señalamos líneas arriba. Padilla Bendezú, partiendo de una referencia del manuscrito, que dice "aunque falta por poner todos los pueblos q' lo tengo el original escrita" (Guaman Poma, 1615, p. 1074 [1084], se inclina a pensar que "el cronista tenía un original que corrigió y copió de nuevo (...), no nos referimos a los apuntes o notas de recopilación, sino a un original de la obra completa” (1979: 85). Estas impresiones fueron confirmadas por el estudio codicológico emprendido por Rolena Adorno (2002b), pues arrojó como resultado que el "procedimiento composicional [seguido por Guaman Poma] sugiere que ésta es la copia final de un borrador previo" (s.n.). A estos hallazgos, Ossio agrega que en el expediente Prado Tello y en los documentos publicados por Zorrilla, referido al litigio sobre tierras en Chupas, que enfrentó durante toda la última década del siglo XVI a los Chachapoyas y Yarovilcas, y donde Guaman Poma actuó como defensor de la última, "es posible deducir que algo del contenido de su manuscrito ya está presente en la argumentación que presentó a las autoridades judiciales de aquella época” (2008: 51).

El tercer tema tuvo que ver con el título del manuscrito, donde vemos que en el mismo se propone nueve formas distintas de referirla: El primer nueva corónica y buen gobierno (p. 0), Primer nueva corónica de las Yndias del Pirú (p. 10 [10]), Primer [coronica] Nueva Corónica y Buen Gobierno deste reyno (p. 1 [1]), Primer y nueva corónica y de uien uiuir (p. 11[11]), Nueua corónica y buen gobierno deste rreyno (p. 1128[1138]), Corónica nueua y buen gobierno de este rreyno (p. s.n.[1188]), Libro y crónica (pp. 700 [714], 701[715], 902[916], 1078[1088], 1079[1089], 1168[1178]), Libro y primer corónica(p.737[751]), y Corónica (pp. 15[15], 453[455], 524[528], 616[630], 697[711], 737[751], 961[975], 975[992], 1032[1040], 1079[1089], 1084[1094], 1115[1125], 1168[1178], [sn.1179]. Ante esta diversidad, la mayoría de estudiosos, sin prestarle mucha atención a las distintas nominaciones, refiere el título de la portada -El primer nueva corónica y buen gobierno-, al margen de la incorrección gramatical, e incluso, su abreviación a Nueva corónica y buen gobierno, Nueva corónica o, simplemente, Nueva crónica. Una de las pocas estudiosas que ha reparado en este tema es Rolena Adorno (2002), centrándose en la modificación que hace el autor del título de la portada, que en un inicio era El primer i nueva corónica i buen gobierno, y luego, según se puede observan en el edición digital del manuscrito, ocultó las dos 


\section{Carlos García Miranda}

“i” con un dibujo, quedando El primer nueva corónica y buen gobierno. Adorno propone que dicha modificación debió realizarse en las últimas revisiones que el autor hizo al manuscrito -sobre la que hay huellas en todo el texto-, con la intención de enfatizar los objetivos de su escrito, que era presentar "una 'nueva crónica' de la historia andina y un tratado sobre el 'buen gobierno' o reforma gubernamental del Perú virreinal" (s. n.). La necesidad de dicho énfasis pudo ser consecuencia de su atención a los cambios en el escenario político que en ese momento estaba ocurriendo en la administración colonial, y que le obligaron no sólo a modificar el título, sino incluir notas al margen, páginas enteras y hasta nuevos capítulos. La naturaleza de las modificaciones y contenido de las adiciones realizadas antes de sellar su manuscrito, también revelan la agudización de los problemas que desde el inicio el manuscrito se propuso tocar, como la falta de recursos económicos de la administración colonial y, sobre todo, la inminente destrucción de la sociedad andina ${ }^{6}$.

Sobre este mismo punto, el título de la portada del manuscrito, también resulta interesante la lectura de Alberdi Vallejo, pues propone que el título "El primer nueva corónica y buen gobierno" debe su incorrección gramatical al hecho de ser una traducción del quechua. Argumenta que la expresión de dicho título en quechua sería: "Musuq mita allichasqa allin kawsay kamachikuytawan", donde la estructura /"Musuy mita allichasqa"/ podría traducirse como "el primer tiempo nuevo a partir de ahora". En la traducción al castellano se usa el artículo "el" en vez de la forma correcta "la", porque el primero está determinado por el "monema relativo quechua /"mita"/ (tiempo cronológico)" (2008: 10), que se traduce en masculino -"el primer tiempo nuevo"-, y que al ser incluida en la frase "corónica y buen gobierno", el autor se vio obligado a alterar la sintaxis. En ese sentido, el título de la portada estaría privilegiando su base lexical quechua, antes que la castellana, produciendo así la incorrección.

Ambos planteamientos, el de Adorno y Alberdi, sugieren diversas lecturas. Por ejemplo, que la diversidad de títulos del manuscrito se debe a que proceden

6 Al respecto, afirma Adorno: "Fue en estas revisiones finales que intentó reforzar los objetivos orientados al futuro de su programa de remedios y que pudo haber sentido que su interés había cambiado fuertemente en esa dirección: El Virrey Mendoza y Luna apareció como un ejemplo viviente de gobierno justo. A través de su retrato y de otras adiciones a la obra, Guaman Poma enfatizó la importancia de la minería para la economía española y la amenaza de destrucción que planteaba a la sociedad andina. La conducta de los sacerdotes cristianos en el Perú fue también objeto de su intensa preocupación, y "Camina el autor" añadió un lamento indignado y horrorizado acerca de las campañas de extirpación de idolatrías de Francisco de Ávila en Huarochirí. Este último capítulo también renovó la protesta de Guaman Poma sobre los efectos devastadores del mestizaje sobre la composición racial, étnica y social del Perú andino. La narración de la historia, una de las dos metas gemelas del libro, viene a ser, relativamente hablando, eclipsada por su pareja equivalente, el desenmascaramiento de los abusos coloniales y la exposición de propuestas para la reforma administrativa”, (s.n). 
de originales distintos que al ser copiados en la versión final mantuvieron su titulación de origen, y que no sólo habría un borrador del manuscrito, sino varios e, incluso, escritos en tiempos distintos, y más aún, que procedan de varios autores, tal vez de un equipo que responda a un proyecto grupal. Asimismo, que la incorrección gramatical del título de la portada se deba a que el autor del manuscrito haya estado pensando en quechua el significado de tal titulación al momento de traducir el título, revelando así su condición de nativo quechua hablante.

Un cuarto tema es el de la forma narrativa o discursiva a la que es posible adscribirla. El término comúnmente usado para referirse a El primer nueva corónica y buen gobierno es el de crónica. Pietschmann la denominó también "Crónica ilustrada" (1908: 201), sin más argumento que la abundante iconografía que la acompaña. Más adelante, Wachtel solía usar indistintamente códice o crónica (1973: 167 y 168), también sin mayor sustento que su semejanza con los códices ilustrados mexicanos. John Murra la denominó "carta al rey" o "memorial", partiendo de su filiación -hallazgo de Porras Barrenechea- con "las soluciones (...) que se desarrollaron en los Andes entre los señores étnicos y (...) cierto círculos europeos, minoritarios pero influyentes" (1997: LIII), abriendo así una línea de investigación que la vincula a la administración colonial, pues permite conectarla con los círculos de poder tanto español como étnico. Juan Ossio (1973) también propuso esa filiación, incluso mucho antes que Murra, y ha vuelto a presentarla en un libro reciente, subrayando su naturaleza de Carta al rey, y afirmando que "esta carta no es enviada por una persona ordinaria sino por un Príncipe (Auqui), la 'Segunda Persona del Inca', quien, como tal, podía transmitir la voz unísona de toda la población indígena" (2008: 238). Por su parte, Raquel Chang, la incluye dentro de las "crónicas mestizas", noción que recoge de Martín Lienhart, y que le permite insistir en su naturaleza histórica (1988: 27-30).

En general, hasta este punto de la discusión se hizo evidente la dificultad de inscribirla en unos rígidos formatos de clasificación colonial -crónica o historia- que no resistían su complejidad, tal como se puede apreciar en el cuadro clasificatorio historiográfico de Porras Barrenechea, donde habría que considerarla como una crónica pos toledana, hasta el modelo -más avanzadopropuesto por Walter Mignolo (1992), cuyo corpus no incluye El primer nueva crónica y buen gobierno, el cual tendría que ser considerado como un discurso cultural cuya formación textual es no-literaria, dentro de la cual el tipo de discurso que le corresponde es la crónica, en la que conformaría una familia textual denominada crónicas indígenas, junto al Inca Garcilaso de la Vega, Titu Cusi Yupanqui y Joan Santa Cruz Pachacuti. Inclusión discutible por la naturaleza de cada una de ellas. 
López Baralt hará patente esta dificultad de clasificación del manuscrito, develando su carácter heterogéneo, pues constituye en sí misma, una "crónica, memorial, carta, libro de consejo de príncipes" (1988: 481). Así, se inclinará más por tratar de identificar el núcleo duro de su mensaje, adscribiéndolo a la literatura de régimen principium o de consejos al príncipe. En esta línea de investigación Pérez Cantó postulará al manuscrito como un memorial arbitrista (1996: 141-188), tesis ya planteada por Adorno y López Baralt, pero que Pérez Cantó amplía y profundiza. Por su parte, en esta misma línea de investigación, Rolena Adorno (1991), a la vez que acepta la naturaleza histórica -de acuerdo con la concepción de historia de su tiempo (s. XVI-XVII)- del manuscrito, lo vinculará con el sermón eclesiástico (pp. 11-22), de cuya técnica de persuasión Guaman Poma se apropiará exitosamente. Finalmente, resulta sugerente la vinculación que realiza Rocío Quispe-Agnoli con el Memorial de remedios (2009: 211-237).

Un quinto tema, que desde su descubrimiento llamó la atención de los investigadores, fueron los 399 dibujos que integran el manuscrito. Tempranamente, se definieron dos líneas de lectura. La primera, se inclinó a insertar los dibujos dentro de la tradición occidental, considerándolo una copia de los grabados del siglo XVI y XVII. En esta línea, cabe mencionar el último estudio de Augusta E. Holland (2008). Su tesis es que los dibujos responden a libros modelos utilizados para pintar murales en las iglesias, dibujar figuras individuales para iluminar libros y escribir con caligrafía ornamental. Lamentablemente, no se ha podido ubicar en el Perú alguna copia de estos libros modelos que corresponda con las fechas de elaboración de manuscrito. La segunda se interesó por conectarla con la tradición nativa, vinculándolo con los dibujos de los keros y el arte popular andino. Aquí, resulta interesante la lectura de Emilio Mendizábal Losack que postula al autor como un quellcakamayoc, o pintor prehispánico (1961: 228-230). En base a sus investigaciones, se han producido estudios sobre los tocapus y los quipus dibujados en el manuscrito (Urton, 2005).

Finalmente, cabe apuntar como sexto tema el recorrido seguido por el manuscrito desde su culminación en el Perú, hasta su hallazgo en la Biblioteca Real de Copenhague. Lo primero que interesó indagar fue sobre sus posibles destinatarios. En la última página del manuscrito se señala que "se presentó antel..." (p. s.n. [1088]), dejando un vacío sobre la identidad de la persona que envió el manuscrito. Luego, en la carta de Guaman Poma dirigida al rey Felipe III, encontrada por Guillermo Lohmann en el Archivo de Indias, se consigna, por un lado, un lugar de remisión: el "pueblo de Santiago de Chipao de la provincia de los Andamarcas Lucanas Soras, distrito de la ciudad de Huamanga" (1945: 327), y una fecha: 14 de febrero de 1615. Estos datos han aportado en la confirmación del lugar de residencia del autor del manuscrito, la zona del 
repartimiento de Andamarca, donde el pueblo de Santiago de Chipao es vecino de San Cristóbal de Sondondo, pueblo originario del autor. Asimismo, permite establecer una fecha de culminación del manuscrito. Por otro lado, se hace mención que no era la primera vez que enviaba una carta al rey informándole sobre su manuscrito ${ }^{7}$, sobre todo, que propone a Luis de Velasco, marqués de Salinas, a la sazón virrey del Perú (1596-1604), como alguien que conoce el manuscrito y, además, capaz de avalarlo ante el rey ${ }^{8}$. Esto revela que el manuscrito llegó a conocerse en la corte virreinal, donde pudo ser conocido por los dos únicos cronistas en cuyas obras se encuentran referencias al contenido de la obra. Uno de ellos es fray Buenaventura de Salinas y Córdova, en cuya crónica, como referimos líneas arriba, se hace referencia a las cuatro edades del hombre prehispánico mencionada en El primer nueva corónica y buen gobierno. El otro es el jesuita Anello Oliva (1998), el único cronista que refiere el nombre de Guaman Mallqui, el padre de Guaman Poma9 . Luego hay dos pistas a seguir: una, defendida por Porras Barrenechea, Padilla y Adorno, corresponde a su llegada a la biblioteca del Duque de Olivares, de donde la adquiriría el coleccionista y diplomático danés Cornelius Pederse, quien la haría llegar a la Biblioteca Real, donde se tiene documentación de su existencia desde el siglo XVIII; otra, defendida por Alberdi Vallejo, es la que plantean algunos memoriales de curacas que hacen llegar la crónica a España a través de un emisario, pero no tiene éxito, así como la sobrevivencia de la crónica en la memoria oral andina a través de mitos y leyendas.

\section{Referencias bibliográficas}

ADORNO, Rolena (1991). Guaman Poma. Literatura de resistencia en el Perú colonial. México DC, Siglo XXI.

7 "Como fue muy notorio de que por otras cartas antes de ahora tengo dado cuenta a Vuestra Majestad acerca de esto y de otras cosas muy del servicio de Vuestra Majestad" (Lohmann, 1945, p. 327)

8 “[...] que siendo necesario el querer saber Vuestra Majestad de cómo soy, el contenido podrá dar a Vuestra Majestad entera noticia acerca de ello el marqués de Salinas, presidente del Real Consejo de las Indias, que la tiene de mi persona del tiempo que gobernó este reino, que por ser yo natural y poco inteligente como lo son los españoles para poder encaminar a Vuestra Majestad el dicho tratado de corónica general, no lo envío en esta armada a España” (Lohmann, 1945, p. 327).

9 “Pero no lo permitió Dios por la razón dicha antes, quiso que así Uáscar como Atahualpa procurasen el favor y amistad de los españoles < tachados: castellanos > y de tal suerte que siéndolo del uno dellos, quedassen por enemigos declarados del otro. Con este fin y blanco, despachó Uáscar una embascada [sic] con Huamman Mallqui Topa, indio orejón de la Sangre Real a Don Francisco Pizarro, pidiéndole que pues era hijo del Sol y venia a deshacer agravios: deshiciesse el muy exorbitante en que le tenía su hermano Atahualpa. El governador respondió que ya yva de camino para [agregado: aiudar con la verdad y justicia a quien la tuviesse y favorecer a quien lo mereciesse] < tachado: deshacer aquellos agravios y qualesquiera otros que hallase >" [fol. 105r.].

LETRAS 81 (116), 2010 
ADORNO, Rolena (2002a). Un testigo de sí mismo. La integridad del manuscrito autógrafo de El primer Nueva Corónica y buen gobierno de Felipe Guaman Poma de Ayala (1615/1616). Obtenido en http://www2.kb.dk/elib/mss/poma/docs/adorno/2002/ index-esp.htm [10-01- 2010].

ADORNO, Rolena (2002b). Guaman Poma y su crónica ilustrada del Perú colonial: un siglo de investigaciones hacia una nueva era de lectura. Obtenido en http://www2.kb.dk/elib/ mss/poma/presentation/index.htm [10-01-2010].

ALBERDI VALLEJO, Alfredo (2008). Los últimos documentos coloniales relacionados con Guaman Poma. Los curacas rebeldes de Huamanga, 1662-1664. Obtenido en http://alberdi.de/DOCSGPOMA,270808.pdf [10-01-2010]

CHANG-RODRÍGUEZ, Raquel (1988). La apropiación del signo: tres cronistas indígenas del Perú. Temple, Center for Latin American Studies, Arizona, State University.

GEERTZ, Cliffort (1994). Conocimiento Local. Ensayos sobre la interpretación de las culturas. Barcelona, Paidós.

CLIFFORD, Geertz (1998). Géneros confusos. La refiguración del pensamiento social. En Carlos Reynoso (compilador): El surgimiento de la antropología posmoderna. Barcelona, Gedisa Editorial.

HOLLAND, Augusta E. (2008). Nueva corónica: tradiciones artísticas europeas en el virreinato del Perú. Cuzco, Centro de Estudios Bartolomé de las Casas.

LOHMAN VILLENA, Guillermo (1945). "Una carta inédita de Huamán Poma de Ayala”. En Revista de Indias, VI, 20; 325-327.

LÓPEZ BARALT, Mercedes (1988). Icono y conquista: Guaman Poma de Ayala. Madrid, Hyperión.

LORITE MENA, José (1995). Sociedades sin Estado. El pensamiento de los otros. Barcelona, Ediciones Akal.

LOZANO, Jorge (1987). El discurso histórico. Madrid, Alianza Editorial.

MARKHAM, Clements (1939). Sobre la obra de Felipe Huamán Poma de Ayala. En Julio C. Tello (editor). Las Primeras edades del Perú. Lima, Publicaciones del Museo de Antropología.

MEANS, Philip Ainsworth (1939). Algunos comentarios sobre el manuscrito inédito de Felipe Huamán Poma de Ayala. En Julio C. Tello (editor): Las Primeras edades del Perú. Lima, Publicaciones del Museo de Antropología.

MENDIZÁBAL LOSACK, Emilio (1961). Don Felipe Guaman Poma de Ayala, señor y príncipe, último quellcakamayoc. En Revista del Museo Nacional, 30; 228-330.

MIGNOLO, Walter (1992). "Cartas, crónicas y relaciones del descubrimiento y la conquista". En Luis Iñigo Madrigal (coordinador): Historia de la literatura hispanoamericana, I. Madrid, Ediciones Cátedra; pp. 57-115.

MURRA, John (1987). Una visión indígena del Mundo Andino. En Guaman Poma, Felipe: Nueva Corónica y Buen Gobierno [1613]. Madrid, Siglo XXI.

OSSIO, Juan M. (1973). "Guaman Poma: Nueva Crónica o carta al Rey. Un intento de aproximación a las categorías del Mundo Andino". En Ideología Mesiánica del Mundo Andino, Lima.

OSSIO, Juan M. (2008). En busca del orden perdido. La idea de la Historia en Felipe Guaman Poma de Ayala. Lima, Fondo editorial de la Pontificia Universidad Católica del Perú. 
Agenda problemática de El primer nueva crónica y buen gobierno de Guaman Poma de Ayala

OLIVA, GIOVANNI Anello (1979). Historia del reino y provincias del Perú [1631]. Lima, Fondo Editorial de la Pontificia Universidad Católica del Perú.

PADILLA BENDEZÚ, Abraham (1979). Huamán Poma, indio cronista dibujante. México, Fondo de Cultura Económica.

PÉREZ CANTÓ, María Pilar (1996). El buen Gobierno de Don Felipe Guaman Poma de Ayala. Cayambe, Abya-Yala.

PIETSCHMANN, Richard (1939). Nueva corónica y buen gobierno de Don Felipe Guaman Poma de Ayala. Códice peruano ilustrado. Revisión sumaria. En Julio C. Tello (compilador): Las Primeras edades del Perú. Lima, Publicaciones del Museo de Antropología.

PIETSCHMANN, Richard (1975). Relación sobre la crónica ilustrada por el indio peruano D. Felipe Huamán Poma de Ayala. En Guillermo Ludeña de la Vega: La obra del cronista indio Felipe Guaman Poma de Ayala. Lima, Nueva Educación.

PORRAS BARRENECHEA, Raúl (1986). Los cronistas del Perú, 1528-1650 y otros ensayos. Lima, Banco de Crédito del Perú.

REYNOSO, REYNOSO (compilador) (1998). El surgimiento de la antropología posmoderna. Barcelona, Gedisa Editorial.

TELLO, Julio C. (1939). Las Primeras edades del Perú. Lima, Publicaciones del Museo de Antropología.

QUISPE-AGNOLI, Rocío (2009). La fe andina en la escritura. Resistencia e identidad en la obra de Guamán Poma de Ayala. Lima, Fondo Editorial de la Universidad Nacional Mayor de San Marcos.

URTON, Gary (2005). Signos del Khipu Inka. Código binario. Lima, Centro de Estudios Regionales Bartolomé de la Casas.

VATTIMO, Gianni (1985). Las aventuras de la diferencia. Barcelona, Ediciones Península.

WACHTEL, Nathan (1973). Pensamiento salvaje y aculturación: el espacio y el tiempo en Felipe Guaman Poma y el Inca Garcilaso de la Vega. En VV.AA: Sociedad e Ideología. Ensayos de Historia y Antropología andinas. Lima, Instituto de Estudios Peruanos. 